\title{
Intervenção Psicológica em Abrigo para Mulheres em Situação de Violência: Uma Experiência ${ }^{1}$
}

\author{
Madge Porto ${ }^{2}$ \\ Universidade Federal de Pernambuco, Universidade Federal do Acre, Faculdade da Amazônia Ocidental e \\ Conselho Regional de Psicologia 1ํㅡ Região Seção Acre
}

\begin{abstract}
RESUMO - O objetivo deste artigo é descrever a trajetória da reconstrução da proposta de intervenção psicológica em um abrigo para mulheres em situação de violência intrafamiliar e de gênero. O trabalho iniciou-se com o estabelecimento de encontros de supervisão, no formato de intercontrole, do Serviço de Psicologia. Durante esses encontros, houve uma avaliação das atribuições funcionais, que davam referência ao trabalho até então realizado, e o estabelecimento de uma nova proposta de intervenção. A nova proposta tem como referência principal a necessidade de pensar uma intervenção psicológica em um contexto institucional, considerando a temática do enfrentamento da violência contra a mulher.
\end{abstract}

Palavras-chave: intervenção psicológica; gênero; violência contra mulher; abrigo temporário.

\section{Psychological Intervention Experience in A Women's Shelter in Situation of Violence}

\begin{abstract}
The aim of the present paper is to describe the reconstructing of psychological intervention in a shelter for women in situations of intrafamilial and gender violence. This work began with the establishment of clinical supervision meetings, in the format of Psychological Service Intercontrol. During such meetings, there was an evaluation of the functional attributes regarding the work carried out up to that point, and the establishment of a new intervention proposal. The main reference of the new proposal is the need for psychological intervention in the institutional context, considering the issue of confronting violence against women.
\end{abstract}

Key words: psychological intervention; gender; violence against women; temporary shelter.

Este artigo tem por objetivo relatar a experiência profissional de psicólogas no âmbito de uma instituição pública. Será apresentado o processo de mudança nas referências da intervenção psicológica realizada em uma instituição governamental - Casa Abrigo Mãe da Mata do Governo do Estado do Acre, cuja missão é abrigar mulheres em situação de violência intrafamiliar e de gênero juntamente com seus filhos e filhas por um período máximo de 90 dias. Durante esse período, o abrigo oferece proteção e oportunidade para que elas reflitam sobre a vida em situação de violência, assim como as formas de enfrentar essa situação. Na seqüência, serão relatadas as mudanças realizadas nas atribuições do Serviço de Psicologia do abrigo. Para fundamentar a nova proposta, foram feitas discussões sobre as bases que sustentavam a proposta inicial, os resultados obtidos até então e sobre os textos de Severo (1993) e da Secretaria de Políticas para as Mulheres (Brasil, 2003), com o objetivo de promover mudanças na prática institucional.

A principal motivação para escrever este texto foi a constatação da falta de referências para estruturar um serviço de psicologia no contexto de violência contra a mulher. $\mathrm{Na}$ época que iniciamos o trabalho, não encontramos textos que

1 Parte deste trabalho foi apresentada em forma de pôster no IV Congresso Norte Nordeste de Psicologia, de 25 a 28 de maio de 2005 em Salvador - BA. Agradecimentos à psicóloga Lenira Pontes, à Secretaria de Estado de Cidadania e Assistência Social e a equipe da Casa Abrigo Mãe da Mata.

2 Endereço: Rua Álvaro Rocha, 101, Conjunto Universitário 1 Qd. 45, Distrito Industrial, Rio Branco, AC, Brasil 69915-300. E-mail: madgeporto@ ig.com.br apresentassem propostas para a implementação de um serviço de psicologia numa casa abrigo para mulheres. Assim, pensamos que a apresentação de nossa experiência poderá ajudar psicólogas que estejam iniciando um trabalho num abrigo desse tipo.

\section{O atendimento psicológico e as políticas públicas para as mulheres}

$\mathrm{O}$ atendimento psicológico aparece como uma das intervenções relevantes nas políticas públicas de enfrentamento da violência contra a mulher (Brasil, 2003). Existe uma preocupação de garantir à mulher um acolhimento especializado, de forma que não apenas receba a mulher, mas também a ajude a mudar sua vida. (Brasil, 2003; Soares, 2005). Os aspectos psicológicos ganham destaque também diante da queixa recorrente nos serviços especializados de atendimento às mulheres que vivem em situação de violência - delegacias especializadas, casas-abrigo, centros de referência e unidades de saúde - de que a intervenção é difícil ou o atendimento é inútil (Brandão, 1998; Franco, 2002; Meneghel \& cols., 2000; Porto, 2006). Isso porque as mulheres negam a violência, apesar dos sintomas, desistem de prosseguir na responsabilização do agressor ou porque reclamam da situação que vivem e continuam no relacionamento. Assim, há uma expectativa de que a psicologia tem como dar respostas a essas questões.

O feminismo, como referência política e teórica para a organização das mulheres, promoveu uma significativa transformação na compreensão das relações humanas e da organização econômica, política e social do mundo (Pinto, 
2003). A trajetória do movimento feminista promoveu a construção de políticas de inclusão e valorização das mulheres, culminando no início do século XXI, no Brasil, com a criação da Secretaria Especial de Política para as Mulheres - SPM, a realização das I e II Conferências Nacionais de Política para as Mulheres e, por fim, o Plano Nacional de Políticas para as Mulheres - fruto da primeira conferência, que é o documento básico para a implementação das políticas específicas para as mulheres. A SPM está vinculada à Presidência da República, tem status de ministério e possui um orçamento definido (Brasil, 2004). O plano apresenta, como estratégia de proteção às mulheres e consolidação das políticas públicas de enfrentamento à violência, o estabelecimento de redes de cidadania e parcerias. Todavia, já em 2003, um documento elaborado pela SPM apresenta um protocolo de intervenção, entre outros documentos de referência, que orienta e espera que as cuidadoras - trabalhadoras que atendem as mulheres em situação de violência - compreendam as relações de gênero e a violência como um fenômeno relacional. Aponta como ação ideal a abordagem integral, aliando a reestruturação de condições materiais à reestruturação afetiva, emocional e de fortalecimento da condição de cidadania das mulheres. Também destaca a necessidade do conhecimento e manejo dos aspectos cíclicos do processo de violência, de modo que estabeleça mudanças nas construções sociais de identidades e subjetividades, a partir de uma escuta não julgadora.

Outras publicações também apresentam este tipo de demanda, as mais recentes são Soares (2005), Brasil (2006b) e Taquette (2007). Para o desenvolvimento de tal intervenção, a estratégia apresentada consiste de: intervenção em equipe multiprofissional, tendo como referência a interdisciplinaridade para a assistência integral; constituição de redes de parceria; abordagem de grupo e crítica às questões de gênero e da violência contra a mulher (Brasil, 2003). Contudo, não há especificações para a realização do atendimento psicológico nesse contexto e a intervenção a ser realizada é apresentada de forma superficial. Parece haver o entendimento de que a formação em psicologia em si garantiria a realização dessas demandas.

\section{Violência e saúde mental}

Pensar sobre a relação entre a subjetividade e a violência contra as mulheres ainda gera desconforto. As discussões sociológicas apresentam a categoria gênero como explicativa das causas da violência em contraposição às explicações que argumentam a violência como uma patologia mental do agressor ou da vítima. Desse modo, defendem uma forma de responsabilização dos homens autores de violência.

[...] a violência [...] tinha a ver com a discriminação e a submissão das mulheres. [...] Nós em nenhum momento admitimos nenhuma atenção, mais técnica ou um pronto atendimento psicológico, advogado, assistente, para nós isso [...] não tinha nada a ver com a nossa proposta feminista (Diniz, 2006, p. 18, grifo nosso).

Todavia, dentro do próprio movimento, começa a aparecer uma reflexão em que a vitimização começa a ser relativizada. Por exemplo, para Saffioti (2004, p. 125), “[...] o gênero não é tão somente social, dele participando também o corpo, quer como mão-de-obra, quer como objeto sexual, quer, ainda, como reprodutor de seres humanos". A autora refere, ainda, "[...] que se considera errôneo não enxergar no patriarcado uma relação, na qual, obviamente, atuam as duas partes. Tampouco se considera correta a interpretação de que sob $a$ ordem patriarcal de gênero as mulheres não detêm nenhum poder" (Saffioti, 2004, p. 118).

Nesse processo de reformulação, reflexão, inclusive das próprias experiências pensadas ao longo da trajetória feminista, os aspectos referentes à saúde mental começam a ter um espaço entre as próprias feministas, em muitos casos, também psicólogas. Francisquetti (2005) refere que "a existência do inconsciente torna a idéia de violência mais complexa, pois ela pode partir daí - de um outro dentro de nós mesmos. Podemos ser violentos contra nós mesmos ou contra nosso semelhante" (p. 2). Mirim (2006) apresenta um balanço sobre o enfrentamento da violência contra as mulheres do ponto de vista da saúde mental como elemento não só de tipificação da violência - violência psicológica - ou de suas consequiências. A autora dá um lugar para a subjetividade das mulheres em situação de violência, ou seja, inclui o mundo subjetivo, não necessariamente patológico, como elemento constituinte das experiências de violência de gênero.

\section{O atendimento psicológico no contexto da violência contra a mulher}

Durante o processo de construção das políticas para as mulheres em situação de violência, conduzido pelo movimento feminista, a intervenção em psicologia foi se constituindo como relevante (Brasil, 2003; Brasil, 2006a e Brasil, 2006b). A subjetividade dessas mulheres passou a ter um lugar mais importante, mesmo que ainda de forma não explícita, e o atendimento psicológico, por consequiência, também. As tentativas de explicar as causas da violência contra as mulheres, a partir da categoria gênero, não se apresentam como suficientes para explicar por que mulheres que construíram seu referencial de papéis e relações de gênero numa mesma cultura agem de forma diferenciada no que se refere à experiência de viver este tipo de violência. Mesmo quando há a referência de que: "mulheres que suportam violência de seus companheiros são co-dependentes da compulsão do macho e o relacionamento de ambos é fixado, na medida em que se torna necessário. Neste sentido, é a própria violência, inseparável da relação, que é necessária" (Saffioti, 2004, p. 84).

Algumas experiências de atendimento em saúde mental às mulheres em situação de violência mostram as potencialidades do trabalho com o psiquismo. Deparar-se com a ambigüidade da mulher com relação ao agressor e até a si mesma, faz com que se perceba que a violência contra as mulheres se dá em um "[...] contexto complexo, onde estão em jogo, atravessando as pessoas em cena, a realidade externa, a cultura, os fluxos, as forças inconscientes, fantasias, traumas, desejos de vida, desejos de destruição - morte" (Francisquetti, 2005, p. 2).

\section{A Casa Abrigo Mãe da Mata - CAMM}

A Casa Abrigo Mãe da Mata (CAMM) é um espaço criado no ano de 2000 pelo Governo do Estado do Acre, com apoio do Ministério da Justiça e Fundação Banco do Brasil, está 
vinculada à Gerência de Eqüidade de Gênero da Secretaria de Estado de Cidadania e Assistência Social (SECIAS) e tem como objetivo o abrigamento temporário de mulheres e seus filhos menores de 12 anos em situação de violência e/ou em iminente risco de morte (Acre, 2000). A partir de 2001, a CAMM começou a receber as primeiras abrigadas.

A escolha do nome do abrigo baseou-se na lenda da Mãe da Mata, uma sábia senhora que, para os povos da Amazônia, cumpre o papel de ser uma grande protetora e defensora da floresta. Segundo a lenda, essa entidade mitológica pune com rigor aqueles que ousam agredir a floresta e seus habitantes, dessa forma, preservando o seu equilíbrio.

O imóvel foi construído com a finalidade de ser um abrigo e foi projetado com dimensões adequadas para o alojamento de 30 pessoas, entre mulheres, crianças e/ou adolescentes. Está localizado em um bairro residencial de Rio Branco e tem seu endereço mantido sob sigilo. A CAMM funciona 24 horas, com plantões de 12 horas de vigias e monitoras, incluindo sábados, domingos e feriados, e regime de 40 ou 30 horas semanais para os demais cargos. As mulheres chegam à CAMM encaminhadas principalmente pela Delegacia Especializada de Atendimento à Mulher (DEAM) e pela SECIAS. A equipe é composta por: uma gerente administrativa, uma assistente social, três servidoras de apoio à assistente social, uma psicóloga, três educadoras, uma digitadora, uma instrutora de curso profissionalizante, cinco monitoras, quatro vigias, duas cozinheiras, uma auxiliar de cozinha, quatro zeladoras e um motorista Além dos serviços prestados por esses profissionais, existe uma rede de parceiros da área social, médica e jurídica como postos de saúde, hospitais (geral e de saúde mental), Defensoria Pública, centro de referência, Delegacia Especializada de Atendimento à Mulher, Sistema Nacional de Empregos (SINE) e Fundação de Bem-Estar Social do Acre (FUNBESA), que possibilitam o acesso à justiça, à promoção e inserção profissional, à educação e à promoção da saúde física e mental das mulheres e crianças e/ou adolescentes abrigados. Por fim, entre 2001 e 2005, existiram 1.426 abrigamentos.

\section{O serviço de psicologia da CAMM}

O trabalho realizado na SECIAS, capacitação da equipe técnica e de apoio, desde 2003, possibilitou o conhecimento da história da estruturação da CAMM, por meio de depoimentos e documentos, assim como a implementação da proposta de supervisão no formato de intercontrole.

Desde o início do funcionamento da CAMM, várias psicólogas passaram pelo Serviço de Psicologia e, em alguns momentos, esse serviço não foi oferecido. Essa rotatividade, que existe em todas as funções da CAMM e da SECIAS, é conseqüência da falta de servidores concursados e os profissionais que trabalham nesses órgãos são, na maioria, trabalhadores com contratos temporários. Outro aspecto importante é a falta do profissional de psicologia, pois o primeiro curso de graduação em Psicologia do estado só iniciou em 2006. Isso significava, quase sempre, demora na substituição da profissional. A ausência e/ou rotatividade das psicólogas na CAMM foi relatada pelas servidoras, nos momentos de capacitação da equipe, como um elemento limitador no processo de implementação do serviço, pois a elas cabia o papel de "conversar" e de ser "legal", por ouvir os problemas e dar "conselhos" tanto para as abrigadas como para a equipe. Também foi percebido um sentimento de insegurança vivenciado pela equipe no ciclo de vínculos e separações que causou desânimo e desvalorização profissional. Nesse contexto, algumas questões destacaram-se, como: expectativas difíceis de serem realizadas, como o atendimento às mulheres abrigadas e à equipe, ao mesmo tempo, pela mesma psicóloga; e uma valorização do atendimento clínico individual, ou seja, a psicóloga só trabalharia como psicóloga quando atendendo cada um que a procurasse para "conversar" na sala de psicologia. Não eram considerados, segundo as falas dessas servidoras, os estudos de caso como uma atividade da psicóloga, por exemplo. Havia, ainda, mitos e rótulos como "aquela que dá conselhos", "sabe tudo", e "aquela que apóia em todas as horas ", como mencionaram em algumas capacitações.

\section{Duas psicólogas, um desafio: as estratégias do intercontrole}

No processo de capacitação continuada da equipe multiprofissional da CAMM, realizado por mim, que era uma das integrantes da equipe da Gerência de Eqüidade de Gênero da SECIAS, foi identificada a necessidade de iniciar um trabalho de supervisão clínica do atendimento psicológico, pois a psicóloga do abrigo solicitou um acompanhamento sistemático das atividades desenvolvidas, em especial, o atendimento às mulheres abrigadas na CAMM. Assim, com essa demanda, o acompanhamento foi estruturado no formato de intercontrole do Serviço de Psicologia. Isso porque o estabelecimento de uma supervisão clínica tradicional não seria recomendado, pois eu também fazia parte da equipe que trabalhava para o desenvolvimento dos objetivos da CAMM. Contudo, eu era lotada no prédio da SECIAS, e não dentro do abrigo, como ficava a psicóloga que realizava os atendimentos às mulheres.

O trabalho iniciou com a reflexão sobre a prática da intervenção psicológica, até então realizada com base nas atribuições funcionais pré-estabelecidas para o Serviço de Psicologia (Acre, 2001). Os encontros de Intercontrole foram estabelecidos inicialmente com uma freqüência quinzenal, mas as demandas exigiram mais urgência e constância. Assim, optou-se por encontros semanais de duas horas de duração com registro escrito dos assuntos tratados e produção de relatório de atividades. $\mathrm{O}$ desafio que se apresentava era: como delimitar os papéis, assumir novas formas de atuar baseadas numa intervenção psicológica mediada por uma instituição que abriga mulheres em situação de violência e deixar de ser a responsável por outras atividades que não eram específicas da Psicologia?

Nesse processo, considerando-se as atribuições definidas para o Serviço de Psicologia (Acre, 2001), perceberam-se dificuldades e limitações para a realização do trabalho. Com base numa literatura de apoio nas áreas de psicologia institucional, feminismo e gênero (Severo, 1993; Brasil, 2003) e na própria experiência de atendimento no abrigo, foi realizada uma análise de cada atividade atribuída à psicóloga no abrigo (Acre, 2001). Para um melhor entendimento, descreveremos abaixo as atribuições definidas para o serviço de psicologia (Acre, 2001) e as respectivas análises que foram realizadas nos encontros de Intercontrole: 
1. Apoio imediato às abrigadas. Esta atribuição pressupõe que a intervenção psicológica deve ser emergencial para ser eficaz e promover a resolução do caso. Contudo, o serviço de Psicologia funciona apenas durante um horário (manhã ou tarde). Assim, funcionando a CAMM diuturnamente, não era possível um atendimento imediato, mas apenas nos horários de trabalho da psicóloga;

2. Suprir as necessidades psicológicas da equipe. Com base na concepção socio-histórica da Psicologia e nos fundamentos da psicologia institucional, essa atribuição foi considerada um duplo equívoco. Primeiro, porque um psicólogo não "supre" as necessidades psicológicas de seus clientes/pacientes; e, segundo, porque as clientes/usuárias do serviço de uma casa-abrigo para mulheres em situação de violência deveriam ser as mulheres abrigadas, e não a equipe. Por fazer parte da equipe do abrigo, ficou entendido que era inviável o trabalho de intervenção psicológica a essa mesma equipe e, por isso mesmo, a intervenção teria como objetivo trabalhar a subjetividade no sentido de restabelecer o equilíbrio emocional das mulheres abrigadas;

3. Facilitar o processo de socialização equipe/abrigadas e intermediar as relações interpessoais. Mais uma vez, a equipe é apontada como objeto de intervenção da psicóloga, como se, para o Serviço de Psicologia, a clientela do abrigo e a equipe que lá trabalha ocupassem o mesmo lugar e a psicóloga outro lugar diferente dos citados. Nesse ponto, foi considerado que a psicóloga faz parte da equipe e, nessa condição, como qualquer outro membro da equipe, teria um papel de facilitadora do contato entre a abrigada e a equipe do abrigo quando fosse ela quem recebesse/acolhesse inicialmente a abrigada;

4. Colaborar com os demais setores. Nesta atribuição fica explícita a visão do psicólogo como aquele que pode "ajudar em tudo" e "resolver os problemas" de todos. Não há especificação do tipo de colaboração esperada, o que deixa lacunas para expectativas que extrapolam a atuação do profissional em psicologia, como ajudar na parte administrativa e nos encaminhamentos do Serviço Social, para citar dois exemplos;

5. Estudo apurado dos casos (conflitos/necessidades). Esse item foi considerado de extrema importância, já que o estudo de caso é uma atividade fundamental para uma intervenção de qualidade. A explicitação dessa atribuição é muito positiva, pois significa considerar que a intervenção psicológica é mais ampla que o atendimento propriamente dito; e, por fim,

6. Foco do trabalho psicossocial com as abrigadas e filhos. Esse item é o que explicita o foco da intervenção, as mulheres e as crianças que as acompanham e delimita o trabalho no campo psicossocial. Contudo, no conjunto das atribuições, entra em conflito com o item no 2 (Suprir as necessidades psicológicas da equipe).

Por consequiência, depois de toda uma discussão, tendo como referência os pressupostos teóricos citados ao longo deste artigo e identificando uma mistura nas atribuições colocadas para a psicóloga - atender às mulheres abrigadas e à equipe -, começou-se a avaliar a necessidade e viabilidade de redefinição dessas atribuições, principalmente porque a psicóloga do abrigo mostrava-se confusa quanto ao trabalho que precisava desenvolver. Ao mesmo tempo, havia uma demanda significativa da equipe, e até mesmo de seus familiares, pelo atendimento psicológico, o que acarretava prejuízos ao atendimento das mulheres abrigadas, já que o foco do trabalho ficaria desviado.

Por fim, identificamos também a descontextualização do atendimento, ou seja, a referência ao atendimento psicológico desvinculado dos pressupostos feministas e dos conceitos de gênero que dão suporte a essa política pública de enfrentamento da violência contra a mulher. A análise das atribuições existentes, a referência na base teórica das políticas para as mulheres e a experiência desenvolvida a partir dos questionamentos apresentados anteriormente, subsidiaram a definição das novas atribuições do serviço, que foram: 1) Atender as mulheres abrigadas em Grupo Reflexivo; 2) Realizar atendimento individual às mulheres que apresentarem essa necessidade; 3 ) Atender às crianças e adolescentes em grupos; 4) Encaminhar para atendimento psicológico clínico os membros da equipe (e seus familiares) quando houver solicitação; 5) Participar das reuniões de estudo de caso da equipe multiprofissional; 6) Participar dos encontros de intercontrole - supervisão clínica do atendimento psicológico; 7) Realizar o registro dos atendimentos nas pastas das abrigadas (arquivo dos atendimentos), preservando o sigilo profissional e demais questões éticas (Código de Ética do Profissional de Psicologia); 8) Elaborar relatórios mensais dos atendimentos realizados; 9) Participar do plantão de sobreaviso; e 10) Participar da capacitação continuada da equipe multiprofissional (cujas temáticas eram gênero, violência contra a mulher, direitos humanos das mulheres, políticas públicas para as mulheres).

O objetivo seria estabelecer uma referência para o trabalho em psicologia que considerasse a intermediação institucional e o contexto da mulher que vive em situação de violência, cujos fundamentos sociais e culturais são muito fortes. Com base no referencial teórico do feminismo e da categoria de análise gênero, nos quais a política pública do abrigamento está ancorada, seria importante instituir um espaço de atendimento psicológico para a escuta e a reflexão, e que não tivesse como papel principal realizar o tratamento de transtornos psicológicos. Isso também porque o tempo máximo de permanência no abrigo não ultrapassaria três meses, salvo algumas exceções. Nesse contexto, avaliamos que uma intervenção clínica institucional seria mais adequada que uma intervenção baseada na clínica tradicional, como defende Severo (1993).

\section{Resultados Iniciais}

Os resultados aqui apresentados precisam ser avaliados no contexto de uma descrição de experiência profissional. Dessa forma, avaliamos que as mudanças ocorridas trouxeram uma maior organização ao atendimento em psicologia e uma delimitação do papel da psicóloga no abrigo, como foi relatado pelas mulheres abrigadas e pela equipe, respectivamente, nos atendimentos em grupo e nas reuniões de equipe. Todavia, considerando que se trata de um processo contínuo e dinâmico, sujeito a ajustes ao longo do tempo, apresentaremos como resultados o que foi identificado na construção dessa proposta.

A proposta de formar um grupo reflexivo foi bem aceita pelas abrigadas. Elas o nomearam: Grupo Mulheres Unidas 
para Vencer. Nele, foram trabalhados temas como: relações de gênero, violência contra a mulher, auto-estima, planos para o futuro, relacionamento com os filhos, trabalho, entre outros. Com relação às técnicas utilizadas, destacamos as dinâmicas de grupo, leitura de textos, debates livres e desenhos. Para a operacionalização das novas atribuições da psicóloga, optouse por fazer um quadro de horários, organizando todas as atividades que seriam realizadas por ela. $\mathrm{O}$ modelo adotado foi o sugerido por Severo (1993), que destaca o planejamento das atividades, o atendimento em grupo e o estabelecimento de um tempo para os registros dos atendimentos realizados. Cada abrigada tinha uma pasta (arquivo) em que constava, entre outras, a ficha de Atendimento Psicológico. Na ficha, eram realizadas as anotações sobre as temáticas trabalhadas em grupo e as respectivas datas, bem como os atendimentos individuais. Eram registros sucintos, por exemplo, se em um atendimento individual a abrigada relatava como tinha sido seu relacionamento com seus pais, anotava-se na ficha que o tema trabalhado tinha sido "relacionamentos familiares" sem outras informações a respeito. Para o mesmo atendimento, outras informações mais específicas e que precisam ser mantidas sob sigilo, são anotadas em documento de uso exclusivo da psicóloga. Um relatório mensal dos atendimentos psicológicos realizados era entregue à gerência da CAMM, no qual constava o número de atendimentos realizados (em grupo e individual), as participações nas capacitações, intercontrole, fóruns e seminários, reuniões; os encaminhamentos realizados; os contatos com demais profissionais e outras informações julgadas pertinentes.

Em uma avaliação realizada no encontro de encerramento das atividades daquele ano (antes do recesso do fim do ano), foi possível perceber que a proposta de atendimento, fundada na intervenção psicológica mediada pela instituição e considerando o contexto da violência contra a mulher, apontava para resultados mais positivos. Dessa maneira, segundo as mulheres abrigadas, o grupo proporcionava momentos de reflexão sobre suas vidas e sobre a violência sofrida, o fortalecimento da auto-estima e autonomia. Esses resultados são semelhantes aos encontrados por Moreira (1999) em uma pesquisa cujo objetivo era comprovar a indicação do atendimento em grupo como “(...) modalidade de intervenção psicológica” (Moreira, 1999, p. 61) mais adequada nos casos de violência intrafamiliar contra a mulher. Esse estudo também destacou que os conteúdos que emergem dos grupos são basicamente aqueles relacionados à violência e às estratégias de superação dessa situação. Com base no texto de Neves e Nogueira (2003), que apresenta a reflexividade como um instrumento que promove a crítica e defende que, no campo das práticas terapêuticas dirigidas às mulheres, faz-se necessária a criação de "(...) práticas terapêuticas alternativas na Psicologia" (Neves \& Nogueira, 2003, p. 52), consideramos que o trabalho em grupo reflexivo com as Mulheres Unidas para Vencer foi um avanço. Isso porque, após o início do atendimento, com o novo modelo, houve um aumento da demanda por parte das mulheres abrigadas, que foi constatado com o aumento da procura pelo serviço. Tornaram-se freqüentes os pedidos verbais por atendimento ou, de forma indireta, os "passeios pelo corredor" - numa forma de tentar disfarçar a busca direta pelo atendimento - que terminavam na sala de atendimento da psicóloga para informações, atendimento individual e participação no grupo reflexivo.
Por fim, a experiência dos encontros de Intercontrole foi ampliada, ou seja, deixou de ser uma atividade apenas da psicóloga da CAMM para se tornar uma atividade da rede de enfrentamento da violência contra a mulher em Rio Branco. Nesse novo formato, foi nomeada Roda de Conversa em Psicologia. Trata-se de uma supervisão clínica no formato de intercontrole entre as psicólogas que trabalham nas instituições de atendimento que formam essa rede, composta pela Casa Abrigo Mãe da Mata, o Centro de Referência, a DEAM, a maternidade pública, unidades de saúde, entre outros. Nesse espaço, queremos, como nos aponta Machado (2004), discutire dividir as dificuldades teóricas, técnicas e emocionais na intervenção com as mulheres vítimas de violência. É uma tentativa de estabelecer uma estratégia protetora das consequiências da intervenção terapêutica nesse contexto específico.

\section{Considerações Finais}

Escrever este artigo, relatando nossa experiência, faz parte da estratégia pensada para o desenvolvimento de um novo caminho para o atendimento psicológico em instituições públicas no Estado do Acre, e também uma iniciativa de apresentar uma referência para aqueles que precisam iniciar um trabalho semelhante. As dificuldades do Serviço de Psicologia eram percebidas da forma como estavam estabelecidas, uma definição ambígua do papel do psicólogo, o que provocava a demanda da profissional para outros serviços e as expectativas difíceis de serem realizadas, até mesmo incompatíveis como a intervenção em psicologia - "suprir as necessidades psicológicas". Depois dessa avaliação, definimos uma proposta de intervenção e, mesmo sentindo a resistência, seguimos adiante. Precisávamos criar uma nova proposta, uma nova intervenção, principalmente porque compreendemos que a violência contra a mulher é fruto de relações de gênero desiguais que foram construídas histórica e culturalmente (Saffioti, 2004). Assim, não poderíamos reduzir nossa intervenção, ou seja, não poderíamos psicologizar o problema. Precisávamos ousar, pois tínhamos uma nova realidade e um modelo de intervenção que não dava repostas satisfatórias. Por conseqüência, precisávamos buscar instrumentos, teorias e técnicas que nos possibilitassem questionar o que estava estabelecido e propor uma prática nova. Assim fizemos. Ainda estamos estudando, perguntando, enfim, construindo e esse processo convém apresentarmos agora para um debate mais amplo.

\section{Referências}

Acre, Secretaria de Estado de Cidadania e Assistência Social (2000). Projeto Casa Abrigo Mãe da Mata - Projeto de implementação. Rio Branco, AC.

Acre, Secretaria de Estado de Cidadania e Assistência Social (2001). Casa Abrigo Mãe da Mata, Atribuições Funcionais, memória de reunião. Rio Branco, AC.

Brandão, E. R. (1998). Violência conjugal e o recurso feminino à polícia. Em C Bruschini, \& H. B. Hollanda. (Orgs.), Horizontes plurais: novos estudos de gênero no Brasil (pp. 51-84). São Paulo: Editora 34/Fundação Carlos Chagas.

Brasil, Presidência da República, Secretaria Especial de Políticas para as Mulheres (2003). Programa de Prevenção, Assistência e Combate 
à Violência Contra a Mulher - Plano Nacional: diálogos sobre violência doméstica e de gênero: construindo políticas públicas. Brasília: Secretaria Especial de Políticas para as Mulheres.

Brasil, Presidência da República, Secretaria Especial de Políticas para as Mulheres (2004). Plano Nacional de Política para as Mulheres. Brasília: Secretaria Especial de Políticas para as Mulheres.

Brasil, Presidência da República, Secretaria Especial de Políticas para as Mulheres (2006a). Termo de Referência. Brasília: Secretaria Especial de Políticas para as Mulheres.

Brasil, Presidência da República, Secretaria Especial de Políticas para as Mulheres (2006b). Norma Técnica de Uniformização: Centros de Referência de Atendimento à Mulher em Situação de Violência. Brasília: Secretaria Especial de Políticas para as Mulheres.

Presidência da República, Secretaria Especial de Políticas para as Mulheres. Plano Nacional de Política para as Mulheres. Brasília: A Secretaria, 2004.

Presidência da República, Secretaria Especial de Políticas para as Mulheres. Termo de Referência, 2006a.

Presidência da República, Secretaria Especial de Políticas para as Mulheres. Norma Técnica de Uniformização: Centros de Referência de Atendimento à Mulher em Situação de Violência. Brasília: A Secretaria, 2006b.

Diniz, S. G. (2006). Violência contra a mulher: estratégias e respostas do movimento feminista no Brasil (1980-2005). Em S. G. Diniz, L. P. Silveira \& L. A. Mirim, (Orgs.), Vinte e cinco anos de respostas brasileiras em violência contra a mulher: Alcances e Limites (pp. 15-44). São Paulo: Coletivo Feminista Sexualidade e Saúde.

Francisquetti, P. S. N. (2005). Saúde mental e violência: considerações acerca do atendimento em saúde mental a mulheres em situação de violência. Capturado no sítio http// www.mulheres.org.br/violência/documentos/saude_mental_ e_violencia.pdf em 01/05/2005.

Franco, I. R. (2002). Mulheres em situação de violência no âmbito conjugal - As denúncias na Delegacia de Proteção à Mulher de Salvador. Em R. M. Barbosa, E. M. L. Aquino, M. L. Heiborn \& E. Berquó (Orgs.), Interfaces: gênero, sexualidade e saúde reprodutiva (pp. 349-388). Campinas: Editora da Unicamp.

Machado, C. (2004). Intervenção psicológica com vítimas de crimes: dilemas teóricos, técnicos e emocionais. International Journal of Clinical and Health Psychology, 4(2), 399-411.
Meneghel, S. N, Camargo, M., Fasolo, L. R., Mattiello, D. A., Silva, R. C. R. da, Santos, T. C. B., Dagord, A, L., Reck, A., Zanetti, L., Sottili, M. \& Teixeira, M, A. (2000). Mulheres cuidando de mulheres: um estudo sobre a Casa de Apoio Viva Maria, Porto Alegre, Rio Grande do Sul, Brasil. Cadernos de Saúde Pública, 16(3), 747-757. Retirado em 16/09/2004, da SciELO (Scientific Electronic Library Online), http://www.scielo.br/csp.

Mirim, L. A. (2006). Balanço do enfrentamento da violência contra a mulher na perspectiva da saúde mental. Em S. G. Diniz, L. P. Silveira \& L. A. Mirim, (Orgs.), Vinte e cinco anos de respostas brasileiras em violência contra a mulher: Alcances e Limites (pp. 266-287). São Paulo: Coletivo Feminista Sexualidade e Saúde.

Moreira, V. (1999). Grupo de encontro com mulheres vítimas de violência intrafamiliar. Estudos de Psicologia, 4(1), 61-77.

Neves, S. \& Nogueira, C. (2003). A psicologia feminista e a violência contra as mulheres na intimidade: a (re) construção dos espaços terapêuticos. Psicologia e Sociedade, 15(2), 43-64.

Pinto, C. R. J. (2003) Uma história do feminismo no Brasil. São Paulo: Perseu Abramo.

Porto, M. (2006). Violência contra a mulher e atendimento psicológico: o que pensam os/as gestores/as municipais do SUS. Psicologia Ciência e Profissão, 26(3), 426-439.

Saffioti, H. I. B. (2004). Gênero, patriarcado e violência. São Paulo: Perseu Abramo.

Severo, M. C. (1993) Estratégia em Psicologia Institucional. São Paulo: Loyola.

Soares, B. M. (2005). Enfrentando a violência contra a mulher - Orientações práticas para profissionais e voluntários (as). Brasília: Secretaria Especial de Política para as Mulheres.

Taquette, S. R. (Org.) (2007). Mulher adolescente/jovem em situação de violência. Brasília: Secretaria Especial de Políticas para as Mulheres.

Recebido em 14.02.2006

Primeira decisão editorial em 27.07.2006

Versão final em 11.09.2007

Aceito em 14.05.2008 